\title{
Why Did We Think We Dreamed in Black and White?
}

\author{
Eric Schwitzgebel \\ Department of Philosophy \\ University of California \\ Riverside, CA 92521-0201 \\ eschwitz@citrus.ucr.edu \\ (909) 7874288
}

April 30, 2001 


\title{
Why Did We Think We Dreamed in Black and White?
}

\begin{abstract}
In the 1950 's, dream researchers commonly thought that dreams were predominantly a black-and-white phenomenon, although both earlier and later treatments of dreaming presume or assert that dreams have color. The first half of the twentieth century saw the rise of black-and-white film media, and it is likely that the emergence of the view that dreams are black-and-white was connected with this change in media technology. If our opinions about basic features of our dreams can change with changes in technology, it seems to follow that our knowledge of the phenomenology of our own dreams is much less secure than we might at first have thought it to be.
\end{abstract}




\section{Why Did We Think We Dreamed in Black and White?}

In 1951, Calvin S. Hall announced in Scientific American that 29\% of dreams are either entirely colored or have some little bit of color in them. He called such dreams 'technicolored', thereby explicitly comparing them with the colored movies that were becoming increasingly prevalent in the ' 40 's and ' 50 's, and implicitly contrasting them with lower-tech black-and-white movies and dreams.

Some of Hall's contemporaries might have thought him too generous in his estimation of the proportion of black-and-white to colored dreams. Fernando Tapia et al. (1958) found that only about $9 \%$ of a sample of people reporting to Washington University in St. Louis for non-psychiatric medical problems reported having colored dreams, compared with $12 \%$ of neurotic men and $21 \%$ of neurotic women. Warren C. Middleton (1942) found that $40 \%$ of his college sophomores claimed never to dream in color, an additional $31 \%$ claimed that it happened only rarely, and only $10 \%$ claimed frequently or very frequently to dream in color. Interestingly, Middleton found a similar percentage of his college sophomores to report hearing in color, $11 \%$ claiming they frequently or very frequently experienced colored hearing, $68 \%$ claiming they rarely or never did. If one thinks colored hearing is very rare and thus overreported in the Middleton study, one might think that colored dreaming is equally rare and overreported. The fact that Tapia et al. found psychiatric patients to report it more frequently than a control group seems to bolster this interpretation.

Nonetheless, most prominent dream researchers at the time were willing to grant that a sizable proportion of the population at least occasionally had dreams with an element of color. A widely shared opinion was that dreams were predominantly black- 
and-white phenomena, comparable to black-and-white movies, with an occasional splash of color here or there, at least in some people (e.g., Knapp 1956; for retrospective assessments see Yazmajian 1968 and Suinn 1966).

Scientific opinion on this matter changed somewhat in the 1960's, beginning with a report by Edwin Kahn et al. (1962) that when subjects were awakened during REM sleep and questioned about the incidence of color in their dreams, $83 \%$ of dreams were described as having some color. Herman, Roffwarg, and Tauber (1968), using a similar method, found that color dreaming was reported after $69 \%$ of REM awakenings of their subjects. Ralph J. Berger (1963) found between $40 \%$ and $71 \%$ of dreams to contain color, Charles A. Padgham (1975) found about 50\%. Frederick Snyder (1970) suggests that the incidence of color in dreams may even be $100 \%$ ․․

Research on the incidence of color in dreams seems dramatically to have fallen off since the 1960's. I am, however, aware of two polls on the subject in the 1990's. An Austrian survey (Stepansky et al. 1998) found 47\% of respondents claiming not to dream in color - a percentage intermediate between that typical of the 1950's and that which one might expect based on the research of the 1960's. On the other hand, in 1999, America On-Line conducted an informal poll which (by the time 40,000 votes had registered) found $56 \%$ of respondents claiming to dream in color, $4 \%$ claiming to dream in black and white, $27 \%$ claiming to dream in both color and black and white, and 13\% saying they do not know.

I am uncertain what accounts for the substantially higher reportage of colored dreaming in the second survey, but an unscientific and haphazard (but fairly extensive) poll of my acquaintances in the United States seems to confirm the impression given by 
the AOL results: Only a minority claim to dream primarily or exclusively in black and white. I seem to recall from my youth in the 1970's people asking each other whether they dreamed in color or in black and white, but quite a few of my respondents (including older respondents) found my inquiries odd, indicating that although they had never thought about it, it seemed right to say that they generally dreamed in color. This was in fact probably the most frequent response to my questions. It is also suggestive that the rate of color term use in a sample of recent dream reports I have examined appears to be about the same or somewhat higher than the rate of color term use in ordinary English.

Prior to the emergence of black-and-white movies, the incidence of color in dreams seems not to have been an issue. For example, in 1900 Freud appears to take the presence of color in dreams for granted. By my count, six of the twelve long dream reports (over 15 lines of text) in Freud's Interpretation of Dreams (1900/1931) explicitly mention colors other than black, white, and gray. ${ }^{\text {G }}$ Presumably, that percentage would be even higher had Freud been inclined to ask whether there was color in dreams in which it was not spontaneously reported, but he did not pay any special attention to color in dreams (Yazmajian 1964)

Likewise, Aristotle specifically includes colors among the remnants that senseimpressions may leave in the sense-organs and which thus appear to us in sleep (Gallop 1996, pp. 459a23-462a31). Epicurus describes the impressions we have in dreams as having color and shape (Long and Sedley 1987, frag. 15A). Descartes (1641/1984) in his second meditation describes a bit of wax as seeming to change color and wants to grant that such an appearance could come to him in sleep; and, indeed, the skeptical idea that our ordinary waking experience is not qualitatively different from the kinds of 
experiences we have in sleep requires that our dreams have color, since our ordinary

waking experience usually has elements of color. ${ }^{\mathrm{D}}$ In general, I have not observed in my (admittedly desultory) wanderings through the pre-twentieth century literature on dreaming any mention of dreams as lacking color. ${ }^{1}$ Commonly, dreams were compared to paintings or tapestries - typically colored media.

What might explain the mid-century eruption of the opinion that dreaming is predominantly a black-and-white phenomenon? It will likely have occurred to the reader that the first half of the twentieth century was the pinnacle of black-and-white media. Black-and-white photography was first made public in the 1830's, and became increasingly popular through the early twentieth century. Although color photography was invented in the 1860 's, color photos did not become easily attainable to the public until the 1940's. Motion pictures, invented around the turn of the century, were, from very early on, occasionally hand-painted with colors, and two-color filming was sometimes used in the 1920's (for example in Ben Hur). Nonetheless, motion pictures were overwhelmingly black-and-white until the late 1930's when a few 'technicolored' movies such as Gone with the Wind and The Wizard of Oz made a splash. It was not until the 1950's that colored movies became commonplace, and even as late as 1960, a black-and-white film, The Apartment, was mainstream enough to win an Academy Award for best picture. Black-and-white television became widespread after World War II; color television did not become popular until the late 1960's.

It is surely not chance that this flourishing of black-and-white media should coincide with the flourishing of the opinion that dreams are a black-and-white phenomenon. The question is what to make of this fact. 
One possibility, I suppose, is that having all those black-and-white images around caused our dreams to change - that although Epicurus, Aristotle, Freud, and their friends dreamed in color, the average American in 1950 dreamed mostly in black and white and now that our media are largely color again, our dreams are returning for the most part to color. Such a view is not wholly preposterous; things in the world around us surely affect the content of our dreams. After seeing a black-and-white film about Frankenstein's monster, one might have a nightmare in which his black-and-white figure appears as one's tormentor. Since most romantic movies seen by people living in 1950 were black-and-white, perhaps some of those people dreaming of themselves as romantic heroes would paint their dream world in black and white.

Most of our dreams, however (at least most of mine) are not modeled on motion pictures - or at least not in so straightforward a way. Every day a person sees her house and family in full color. It would be odd to suppose that whether she dreamed about them in color would depend on what she sees in the cinema or on the television screen. It seems unlikely that something as peripheral to our cognition as photography, film, and television could have as profound an effect as that - that if the media are predominantly enough black-and-white, they can transform the dreams we have of the colored world around us to dreams of black and white.

I will assume, then, that it is the reporting of dreams that changed rather than their content. If so, somebody got something seriously wrong. The two most obvious possibilities are that our dreams really are predominantly in color (or at least that they are for a majority of people) and consequently the mid-century claim that they are mostly 
black-and-white is mistaken, or that our dreams are predominantly black-and-white and the view that they are colored is the mistake.

One might attempt to defend the view that dreams are predominantly black-andwhite as follows. The failure to notice this feature of dreams by Aristotle, Descartes, and company is due to the lack of black-and-white film media in their time. Without the existence of these media, the idea that something colored might be represented as a black-and-white image would be unfamiliar, and so it would have been natural to assume that since the things dreamed about (family, locations, etc.) are colored in real life, they are colored in dreams. Once black-and-white media gained prominence in the early twentieth-century, people came to recognize that their dream images resembled the images in these media. Now that black-and-white media are losing importance, most people have returned to mistakenly assuming that their dreams are thoroughly colored, though an observant minority maintain that their dreams are mostly black-and-white. People even may mistakenly attribute color to black-and-white dream objects in the course of a dream, just as I might in a dream mistakenly think of something as having the layout of my house when in fact it does not resemble my house at all. Slightly differently, one might simply 'know' that an object is red without seeing a red dream image, just one might in a dream know that someone is one's sister even if she looks nothing like her.

One weakness of this argument is that it is not clear that pre-twentieth century media were predominantly colored. Black-and-white ink sketches and prints were common in some periods, as were monochromatic representations of people and animals 
on pottery and furniture and as sculpture. If dreams were black-and-white, they could as easily have been compared to these media as to colored paintings and tapestries. ${ }^{\text {G }}$

The perhaps more appealing claim is that dreams really are either predominantly or entirely in color and that the mid-century emergence of the claim that they were not was due to an infelicitous but natural comparison between dreams and the flourishing blackand-white media of the time. As paintings and tapestries gave way to photographs and motion pictures, it was natural to update the media to which dreams were compared; and since these media were black-and-white, so also, it came to seem, were dreams. 10 (Perhaps the cinematic device of the "dream sequence" was particularly important in this regard.) As we head into the third millenium, the media will presumably change again to integrate not just visual and auditory but also haptic elements, coming closer to giving us a full fictional sensory experience. A number of people have told me that haptic elements in their dreams are either weak or non-existent - that although, for example, they might seem to be walking around, they do not feel the impact of their feet on the sidewalk or the breeze against their arms. (Perhaps this is why feeling a pinch is sometimes thought to be indicative of waking.) I wonder if, as the media change, our opinions about the presence of such elements in dreams will also change.

Although the view that our dreams are colored attracts me more than the view that they are black-and-white, there is a third possibility that is also worth consideration - the possibility that dreams are neither colored nor black-and-white, that description of them as belonging to either of these categories is misleading.

Consider, as an analogy, a novel. While novels surely are not in black and white, it also seems a little strange to say that they are 'in color'. Certainly novels make fictional 
attributions of color ('she strode into the room in a dazzling, red dress') and refer to objects that normally have a particular color ('she promptly chopped a carrot'). Maybe it makes sense to describe such fictional claims as 'in color' or partly in color. However, most elements of most novel scenes do not have determinate colors in that way. When our character slides into her 1966 Mustang and rumbles away, the scene could be imagined to have any of a variety of colors; her skin might be dark brown or light; the Mustang might be red or black or green; the sky might be blue or gray or dusky or starspangled. And even though we know her dress is red, it actually could be any of a variety of shades, so long as they are suitably dazzling. It is a bit odd to say that this part of the novel - the sentence describing her departure - is 'in color' when the color of so much of it is underdetermined. It is correspondingly a bit odd to say the novel as a whole is in color, though maybe one could get away with saying such a thing if one were careful enough in circumscribing what one meant to imply by the phrase 'in color'.

One might more naturally say that the images that the novel evokes in (most of) its readers are in color (I imagine the Mustang as green and the sky as dusky), but even that may not be quite right. Can't one just imagine her driving away without imagining the colors of the car, road, and sky? If one is reading the novel quickly, one may not have time to piece together a complete colored scene in one's imagination. 11 It does not seem that my imagination, at least, is that rich, that novels play before my mind with all the details of a color movie.

If you find yourself disinclined to think that novels, or the images evoked by novels, are properly described as being either in black in white or in full color, then you might likewise find yourself hesitant to apply the terms 'black-and-white' or 'colored' to 
dreams. Perhaps dream-objects and dream-events are similar to fictional objects and events, or to the images evoked by fiction, in having, typically, a certain indeterminacy of color, neither cerise nor taupe nor burnt umber, nor gray either.

One could go a variety of directions with this thought. One might want, for example, to argue that the objects portrayed in black-and-white movies are of similarly indeterminate color, though they appear on the screen to be gray. Although our heroine is consuming a bell pepper the screen image of which is gray, it does not follow that she is consuming a gray bell pepper. Perhaps, then, the color of the bell pepper is indeterminate. Black-and-white movies, novels, and dreams may be alike in somehow leaving indeterminate the colors of most of their objects - and that is something that color film cannot (or at least cannot easily) do. Perhaps this is a respect in which dreams are more felicitously compared to black-and-white than to color movies.

Which approach to color in dreams is the correct one? I have laid out a few quite distinct possibilities, and I find myself tempted both by the view that dreams are in color and by the view that most objects in dreams have no determinate color. Now it would seem that the phenomenology, that is to say the subjective experience, of dreaming would be quite different in the two cases. If dreams are in color, then the objects in our dreams to whose color we are not attending generally have determinate colors; otherwise, they generally do not. Shouldn't we then be able to reflect on the phenomenology of dreaming to decide the question? Think back to some dream you remember well; did the objects have determinate colors even when the color was not particularly salient? If so, then dreams are in color; if not, they are not. It seems that the experiential difference 
between these two cases is so vast that a moment's reflection should make it obvious which hypothesis is correct.

Here is where I find myself quite thick. Though I remember a dream or two most mornings - and sometimes they have seemed quite vivid - I cannot tell you whether those dreams are in color in the rich sense that a color movie is in color. Now it may be that I am just unusually inept at this task, but I doubt it. The historical swings in opinion about dreaming in black and white suggest that incompetence of the sort I feel is quite widespread, despite the considerable self-confidence people tend to exhibit when questioned along these lines.

Our knowledge of the phenomenology of dreaming seems to be quite poor startlingly poor given the frequency with which we dream and the salience of at least some dreams. This raises the question of whether there is something unique about dreaming that makes its phenomenology particularly elusive or whether our knowledge of other aspects of our phenomenology, for example the phenomenology of pain, imagery, thought, and vision, is equally poor. I am inclined to think the latter, that we know much less about our phenomenology than common sense and philosophy typically allow. Imagery, in particular, raises issues and difficulties similar to those I have been discussing with respect to dreams. Consider this question: If you form a visual image of your house, and you direct your attention to the chimney, how detailed and how colored are the other parts of the image? I see little reason to invest much confidence in the (divergent) answers ordinary people give to such questions. One might also read (with what justice I am uncertain) the debate about the 'picture theory' of imagery as a debate 
partially about the phenomenology of imagination (Kosslyn 1980, 1994, Thomas 1999, Tye 1991).

Of course, the argument that we are pervasively and grossly mistaken about our own subjective experience is best established by the detailed examination of a wide range of cases in which our phenomenal reports are seriously ill-informed. This paper can only be one piece of such a broader project. 
${ }^{1}$ Other researchers find 17\% (de Martino 1953) and 40\% (Husband 1935) of people claiming to see color in their dreams - with women substantially more likely than men to report color.

${ }^{2}$ Richard M. Suinn (1966) describes himself has having intermediate results, finding $35 \%$ of dreams in men and $47 \%$ of dreams in women to have color. See also Gackenbach and Schillig (1983) and Sandyk (1998).

${ }^{3}$ Thanks to Bryan Lee for pointing this survey out to me and forwarding me the results.

${ }^{4}$ This claim is based on my own research. I surveyed dream reports from two recent sources, Cynthia Richmond's columns on dream interpretation in the Los Angeles

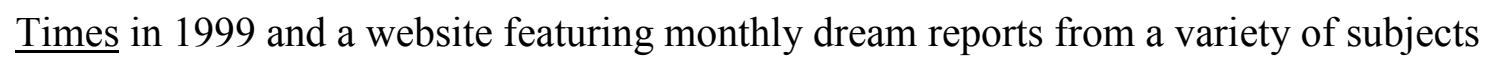
(http://www/lifetreks.com), January 1997 to January 2000. Colors other than black, white, and gray are mentioned 26 times in 14,029 words from these two sources (and about the same rate in each): $0.19 \%$ of all words in the dream reports were color words. Although this may seem like a low rate of color term use, it compares with a rate of approximately $0.14 \%$ in a sample of written English drawn from texts assigned to students in grades three through nine (Carroll, Davies, and Richman 1967), a rate of approximately $0.02 \%$ in a sample of spoken English drawn from psychiatric sessions (Dahl 1979), a rate of approximately $0.08 \%$ in an English corpus drawn from a variety of written sources (Kučera and Francis 1967), and a rate of approximately $0.12 \%$ in the "HAL" corpus drawn from the usenet. (I owe these last data to Curt Burgess, who provided them in personal communication. For more on the HAL corpus see Lund and 
Burgess 1996.) Such statistics are, however, only suggestive, since it could easily be argued that the samples of English used in such surveys are not the appropriate comparison class.

${ }^{5}$ Peter H. Knapp (1956) also counts the frequency of color reports in Interpretation of Dreams, and finds that over half the dreams mention color. However, Knapp treats black, white, and gray as colors for his analysis, and presumably he includes a number of dreams described in fewer than 15 lines.

${ }^{6}$ One contemporary finds color to be a 'pronounced feature' of $21 \%$ of dreams in one sample (Monroe 1898). Edward B. Titchener (1900, p. 268) also briefly mentions "flashes of color" as a primary cause of dreams, although by 1912 he grants that some people see only grays in their dreams. For another interesting transitional work, see Madison Bentley (1915).

${ }^{7}$ More explicitly, in The Passions of the Soul (1649/1985, p. 338), Descartes asserts that "everything the soul perceives by means of the nerves [e.g., sensations] may also be represented to it though the fortuitous course of the spirits [e.g., in dreaming]."

${ }^{8}$ It would be interesting also to look at the mention of color in the dreams of people in cultures without motion pictures or television. Ralph Bolton (1978) reports on color in the dreams of the Quechua Indians in Peru, and finds it infrequently mentioned (white, black and gray in 32 of 498 dream reports; other colors in 19 of 498). However, without knowing how long the dream reports were or the frequency of mention of color in reports of everyday occurrences, the results are difficult to interpret.

${ }^{9}$ One might be tempted to counter with the analogous argument that if dreams were colored, they could, in 1950, have easily been compared to the colored media - paintings 
and tapestries did not cease to exist. However, black-and-white movies had other advantages over the competing media of the time that may have compelled comparison to dreams. They integrated visual imagery with movement and narrative as no other medium previously had been able (except perhaps theater, if that is a medium - why was it not more common to describe dreams as like plays on the mind's stage?). Thus, the defender of colored dreaming could argue that the comparison to black-and-white film was comprehensible despite the media's lack of color, while the defender of black-andwhite dreaming may find it difficult to mount a similar argument explaining the pre- $20^{\text {th }}-$ century comparison of dreams to colored paintings and tapestries.

${ }^{10}$ Since paintings and tapestries don't represent motion well (despite some attempts), I am inclined to wonder whether there were, prior to the twentieth century, debates about whether images in dreams moved, analogous to the black-and-white vs. color debate in the twentieth century. A related issue: Radio was a lively and pervasive medium for fiction in the first part of twentieth century. However, as far as I know, dreams were not compared to radio broadcasts. On the contrary, Knapp $(1953,1956)-$ admittedly rather late if the media comparison is to silent film - describes dreams as mostly soundless - more like silent motion pictures than like 'talkies'.

${ }^{11}$ Although I am not aware of research on the speed at which color imagery in particular is generated, research does suggest that, in general, complex images are more slowly generated than simple ones (Kosslyn 1980).

${ }^{12}$ For helpful discussion of these ideas, thanks to Kurt Boughan, Curt Burgess, Josh Dever, Dillon Emerick, Michael Gordon, Paul Hoffman, Bryan Lee, Tori McGeer, Pauline Price, Richard Reis, Josh Rust, Carol Slater, Nigel Thomas, Emily Undem, Penny 
Vinden, Gary Watson, and audiences from U.C. Riverside (Philosophy Department and coglunch), the Society for Philosophy and Psychology, and the Southern California Philosophy Conference, as well as the numerous others with whom I have chatted about color in their dreams. 


\section{$\underline{\text { References: }}$}

Bentley, Madison 1915: 'The Study of Dreams'. American Journal of Psychology 26, pp. 196-210.

Berger, Ralph J. 1963: ‘Experimental Modification of Dream Content by Meaningful Verbal Stimuli’. British Journal of Psychiatry 109, pp. 722-740.

Bolton, Ralph 1978: 'Salience of Color Terms in the Dreams of Peruvian Mestizos and Qolla Indians'. Journal of Social Psychology 105, pp. 299-300.

Carroll, John B., P. Davies, and B. Richman 1967: The American Heritage Word Frequency Book. Boston: Houghton Mifflin.

Dahl, Hartig 1979: Word Frequencies in Spoken American English. Detroit: Gale Research.

Descartes, Rene 1641/1984: Meditations on First Philosophy, in The Philosophical Writings of Descartes, Vol. II, trans. J. Cottingham, R. Stoothoff, and D. Murdoch. Cambridge: Cambridge.

---- 1649/1985: The Passions of the Soul, in The Philosophical Writings of Descartes,

Vol. I, trans. J. Cottingham, R. Stoothoff, and D. Murdoch. Cambridge: Cambridge.

Freud, Sigmund 1900/1931: The Interpretation of Dreams, trans. A. A. Brill. New York: Carlton House.

Gackenbach, Jayne, and Schillig, Barbara 1983: 'Lucid Dreams: The Content of Conscious Awareness of Dreaming During the Dream', Journal of Mental Imagery 7, pp. 1-14. 
Gallop, David 1996: Aristotle on Sleep and Dreams: A Text and Translation with Introduction, Notes, and Glossary. Warminster, England: Aris \& Phillips. Hall, Calvin S. 1951: 'What People Dream About', Scientific American 184, no. 5, pp. 60-63.

Herman, J., Roffwarg, H., and Tauber, E. S. 1968: 'Color and Other Perceptual Qualities of REM and NREM Sleep', Psychophysiology 5, pp. 223.

Husband, Richard W. 1935: ‘Sex Differences in Dream Contents', Journal of Abnormal and Social Psychology 30, pp. 513-521.

Kahn, Edwin, Dement, W., Fisher, C., and Barmack, J. E. 1962: 'Incidence of Color in Immediately Recalled Dreams', Science 137, pp. 1054-1055.

Kosslyn, Stephen M. 1980: Image and mind. Cambridge, MA: Harvard.

---- 1994: Image and brain. Cambridge, MA: MIT.

Knapp, Peter H. 1953: 'The Ear, Listening, and Hearing', Journal of the American Psychiatric Association 1, pp. 672-689.

---- 1956: 'Sensory Impressions in Dreams', Psychoanalytic Quarterly 25, pp. 325-347.

Kučera, Henry, and Francis, W. Nelson 1967: Computational Analysis of Present-Day American English. Providence: Brown.

Long, A. A., and Sedley, D. N. 1987: The Hellenistic Philosophers, Vol. 1. Cambridge: Cambridge.

Lund, Kevin, and Burgess, Curt 1996: 'Producing High-Dimensional Semantic Spaces from Lexical Co-Occurrence', Behavior Research Methods, Instruments \& Computers 28, pp. 203-208. 
de Martino, Manfred F. 1953: 'Sex Differences in the Dreams of Southern College Students', Journal of Clinical Psychology 9, pp. 199-201.

Middleton, Warren C. 1942: 'The Frequency with Which a Group of Unselected College Students Experience Colored Dreaming and Colored Hearing', The Journal of General Psychology 27, pp. 221-229.

Monroe, Will S. 1898: 'Einige Experimente über Gesichtsbilder in Traum', $\underline{\text { American }}$ Journal of Psychology, 9, pp. 413-414.

Padgham, Charles A. 1975: 'Colours Experienced in Dreams', British Journal of Psychology 66, pp. 25-28.

Patalano, Frank 1984: 'Color in Dreams and the Psychoanalytic Situation', The American Journal of Psychoanalysis 44, pp. 183-190.

Sandyk, Reuven 1998: 'Treatment with AC Pulsed Electromagnetic Fields Induces Vivid Colored Dreams in Multiple Sclerosis', International Journal of Neuroscience 96, pp. $45-52$.

Snyder, Frederick 1970: ‘The Phenomenology of Dreaming', in Madow, Leo and Snow, Laurence H. (eds.) The Psychodynamic Implications of the Physiological Studies on Dreams. Springfield, IL: Charles C. Thomas.

Stepansky, R., Holzinger, B., Schmeiser-Rieder, A., Saletu, B., Kunze, M., and Zeitlhofer, J. 1998: ‘Austrian Dream Behavior: Results of a Representative Population Survey', Dreaming 8, pp. 23-30.

Suinn, Richard M. 1966: ‘Jungian Personality Typology and Color Dreaming', New York (State) Mental Hygiene Department Psychiatric Quarterly 40, pp. 659-666. 
Tapia, Fernando, Werboff, J., and Winokur G. 1958: 'Recall of Some Phenomena of Sleep', Journal of Nervous and Mental Disease 127, pp. 119-123.

Tauber, Edward S. and Green, M. R. 1962: ‘Color in Dreams', American Journal of Psychotherapy 16, pp. 221-229.

Thomas, Nigel 1999: ‘Are Theories of Imagery Theories of Imagination? An Active Perception Approach to Conscious Mental Content', Cognitive Science 23, pp. 207245.

Titchener, Edward Bradford 1900: A Primer of Psychology. New York: MacMillan.

---- 1912: 'Prolegomena to a Study of Introspection', American Journal of Psychology 23, pp. 427-448.

Tye, Michael 1991: The Imagery Debate. Cambridge, MA.

Yazmajian, Richard V. 1964: 'Color in Dreams', Psychoanalytic Quarterly 33, pp. 176193.

---- 1968: 'Dreams Completely in Color', Journal of the American Psychoanalytic Association 16, pp. 32-47. 